\section{Director of Wellcome centre resigns over damning report}

\section{London}

Roy Anderson, one of Britain's leading epidemiologists, has resigned as director of an Oxford-based research centre financed by the Wellcome Trust, following two damning reports on the way that the centre has been managed.

An independent management report, which criticizes both the University of Oxford and the trust for not keeping a close enough eye on the situation, will be a blow to both institutions.

The Wellcome Trust, which funds the Centre for the Epidemiology of Infectious Diseases at Oxford, this week released a management review and interim audit review of the centre. Both reviews began earlier this year when Anderson was suspended following a series of complaints about his behaviour during staff appointment procedures (see Nature 403, $353 \&$ 695; 2000).

The reviews found that centre research staff supported by the trust had accepted commercial grants worth $\mathfrak{£ 2 5 0 , 0 0 0}$ from a number of sources including the company IBHSC Ltd in which Anderson owns a third of the shares.

But Anderson had failed to make a full disclosure of his interests in his company IBHSC Ltd to either the trust or the university, as required of Wellcome grant holders.

However, the interim audit, which was produced jointly by PricewaterhouseCoopers and the university's chief internal auditor, found no evidence of financial impropriety.

The independent management review was chaired by Sir Dai Rees, the former chief executive of the Medical Research Council. Its report says that the centre suffers from "autocratic management", festering tensions and disagreements, discouragement of independent views and growing tensions between the centre and the university's department of zoology to which it belongs.

Mike Dexter, director of the Wellcome Trust, says trustees were "obviously distressed" at the events surrounding the centre. He said there was "no question of the scientific credibility of Roy Anderson or the centre. It is doing first class work and our priority is to maintain that."

Anderson remains a governor of the Wellcome Trust, although Dexter says that his position "remains to be discussed".

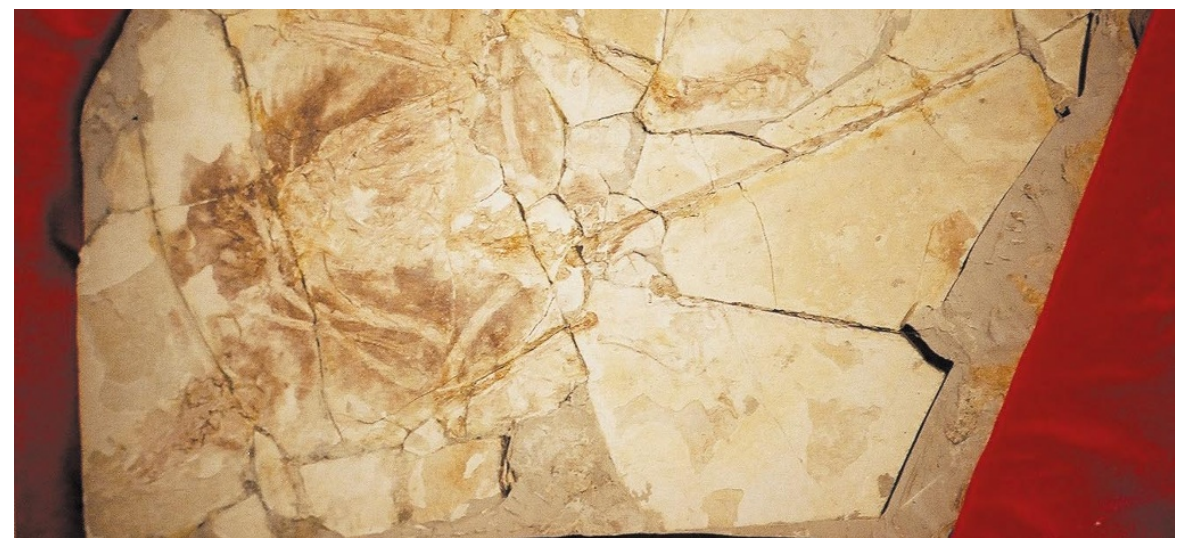

Missing link: the 'Archaeoraptor' fossil is a composite, not a new species.

\title{
Fake bird fossil highlights the problem of illegal trading
}

Fort Lauderdale, Florida

It could have been an important clue to dinosaur and bird evolution. But a panel of palaeontologists last week confirmed that a fossil of a toothed bird - originally thought to be an important new species - is a composite of a least two separate specimens.

The fossil, which is thought to have been smuggled out of China, was bought early last year by amateur collectors, who paid $\$ 80,000$ for it at an Arizona mineral show (see Nature 403, 689; 2000). It will be returned to China in June as a result of negotiations completed last week while the fossil was being analysed at the US National Museum of Natural History in Washington DC.

According to several palaeontologists, the specimen still might have implications for the evolution of birds, and scientists at the Institute of Vertebrate Paleontology and Paleoanthropology in Beijing are keen to study it.

But "it took about five minutes" to determine that the fossil was a composite, says Mark Norell, chairman of vertebrate palaeontology at the American Museum of Natural History in New York, and a member of the five-scientist panel.

According to Norell, the fossil tail of a primate bird had been inserted into the slab with the fossil remains of a more advanced bird, creating the appearance of a unknown specimen. Such fossils are typically altered in China to boost their value on the global underground market — they are classed as 'national treasures' in China, and cannot be sold legally.

The fossil — never named scientifically in a peer-reviewed journal, but known as 'Archaeoraptor' - was included in an article on bird evolution in National Geographic last November. The magazine had expected a paper on the specimen to appear in a scientific journal before its own article was published. But both Nature and Science declined to publish a submitted manuscript on the fossil.
National Geographic funded last week's analysis of the specimen, flying in a Chinese scientist and paying $\$ 5,000$ for the facing, counter-slab of parts of the 'Archaeoraptor' specimen. This counter-slab definitively proved the fossil's composite nature.

'Archaeoraptor' was discussed last week at the first Florida Symposium on Dinosaur Bird Evolution in Fort Lauderdale, sponsored by the Graves Museum of Archaeology and Natural History. But a lecture on the fossil by Stephen Czerkas, the amateur collector who first purchased it, threw little light on the controversy surrounding the specimen.

Indeed Czerkas, who directs a small museum in Blanding, Utah, also displayed and gave a talk on a second bird fossil. Several academic palaeontologists suggested this might also come from China, raising questions about whether the specimen had been smuggled out before Czerkas obtained it.

During two talks, Czerkas did not explain the origins of either specimen, or describe any scientific exchange with Chinese institutes. But he did publicly acknowledge for the first time that 'Archaeoraptor' was a composite.

Referring to the new fossil as "an arboreal theropod" with "remarkable implications", Czerkas claimed that it "represents a previously unknown lineage of dinosaurs that could climb".

But Kevin Padian, a curator at the University of California's Museum of Paleontology, said: "The idea that you look at a couple of features and say it lived in a tree is just not science. Such a determination requires a detailed study of all joints and motions." Czerkas refused to be interviewed after his talks.

The new specimen prompted Padian to call for aggressive new efforts by scientists and authorities to address the illicit trade in fossils. An international protocol is needed to keep the specimens in China "where they belong", he said.

Rex Dalton 